\title{
Hydroxy- and Aminoethyl Imidazolines of Cottonseed Oil Fatty Acids as Additives for Diesel Fuels
}

\author{
Vaqif Maherram Abbasov¹, Tarana Aslan Mammadova', Khayam Rahim Veliyev', \\ Khayala Hamlet Kasamanli ${ }^{2}$ \\ ${ }^{1}$ Institute of Petrochemical Processes Named after Yu. G. Mamedaliyev of National Academy of Sciences of \\ Azerbaijan, Baku, Azerbaijan \\ ${ }^{2}$ Ganja State University, Ganja, Azerbaijan \\ Email: iranasafarli@gmail.com
}

Received 22 February 2015; accepted 15 March 2015; published 25 March 2015

Copyright (C) 2015 by authors and Scientific Research Publishing Inc.

This work is licensed under the Creative Commons Attribution International License (CC BY). http://creativecommons.org/licenses/by/4.0/

(c) (i) Open Access

\begin{abstract}
In the research, aminoethyl imidazolines of cottonseed oil fatty acids with diethylenetriamine have been synthesized using the ultrasonic device creating the effect of cavitation. The yield of imidazolines was $90 \%-95 \%$. The influence of the synthesized imidazolines on lubricity quality of low sulfur diesel fuels having low lubricating quality was studied. The results showed that at concentrations 200 - $250 \mathrm{ppm}$ the synthesized imidazolines can be applied as additives enhancing lubricity quality of diesel fuels.
\end{abstract}

\section{Keywords}

Cavitation, Imidazoline, Cottonseed Oil Fatty Acids, N-Hydroxyethyl Ethylenediamine, Diethylenetriamine

\section{Introduction}

Currently imidazolines and their derivatives are used as additives to diesel fuels, although it should be noted that works in this direction have just begun and need systematic studies [1]-[16].

Thus, in the work [7] the possibility of using an additive, containing (wt\%) alkyl $\left(\mathrm{C}_{3}-\mathrm{C}_{18}\right)$ nitrate $75-90$ by weight, anticorrosion component 5 - 15 by weight, a hydrocarbon fraction boiling in the range $120^{\circ} \mathrm{C}-270^{\circ} \mathrm{C}$ to $100 \mathrm{wt} \%$, was shown. Anticorrosive component is selected from the group consisting of 3, 4, 4-trimethyl-2phenyl octane acid, 2-imidazoline, alkyl $\left(\mathrm{C}_{4}-\mathrm{C}_{9}\right)$ thiazolidine, $\mathrm{N}$-oleilsarkozin. The additive may further contain 
a copolymer based on ethylenically unsaturated monomers in an amount of $0.5-1.5 \mathrm{wt} \%$. Diesel fuels based on the base fuel contain the above-described additive in an amount of $0.01-0.8 \mathrm{wt} \%$. As the base fuel petroleum diesel fuel or gas condensate fuel may be used. The technical result is an improvement of anticorrosive properties and combustion quality, extension of storage life to $2-3$ years, which is especially important in cold climates where condensation occurs and droplets of moisture favor the processes of hydrolysis and oxidation of fuels, thereby diesel fuels containing the known additives are prone to corrosion.

The use of the proposed additive in diesel fuels can not only improve the performance of petroleum and gas condensate diesel fuels, but also increase their storage life to 2 - 3 years compared with diesel fuels being used which have storage life of no more than 1 - 1.5 years.

As an additive reducing toxicity of exhaust gases and improving the smoke suppression properties of diesel fuels in the work [8] barium alkyl phenolate and the additive selected from the group: the reaction product of carboxylic acid with diethylenetriamine, the reaction product of sulfocarboxylic acid with diethylenetriamine, the reaction product of alkyl phenol with hexamethylenetetramine, diethylenetriamine and boric acid with the following ratio of components, wt\%: barium alkyl phenolate $0.045-0.4$; additive $0.005-0.1$; diesel up to 100 were used.

In the patent [9] as a multifunctional additive, namely a demulsifier, corrosion inhibitor and/or an additive for lowering the pour point oxyalkylated fatty amines and fatty amine derivatives are used.

As is known, the increase of the efficiency of fuel combustion in the internal combustion engine increases the engine power, fuel economy, and reduces particulates in the exhaust gases. In order to achieve all of the abovementioned parameters in [10] the additive containing the following components: di-tert-butyl peroxide, imidazoline of tall oil fatty acids and neodecanoic acid were used. In this composition, the organic di-tert-butyl peroxide is a source of supplemental oxygen and free radicals for acceleration of combustion chain reaction for the diesel fuel. Imidazolines of tall oil fatty acids act as an ashless detergent to maintain fuel system cleanliness (including combustion chamber and injector), absorb moisture, preventing rust and corrosion; neodecanoic acid acts as an initiator and stabilizer for the above-mentioned organic peroxide and provides resistance of diesel fuel to microbes which is also important when using biodiesel fuel.

Alkyl imidazolines with varying degrees of ethoxylation were studied as antioxidants of hydrocarbons of fuel fractions in the work [11]. It was found that while using the above-mentioned imidazolines the time of oxidation inhibition is approximately two times higher than when using the commercial oxidation inhibitor ZDDP.

In the present work the process of obtaining amino- and hydroxyethyl imidazolines of cottonseed oil fatty acids using ultrasonic cavitation has been investigated and the synthesized imidazolines were added to diesel fuels to improve their lubricity.

\section{Materials and Methods}

As initial reactants there were used N-hydroxyethyl ethylenediamine (HEEDA) produced by "Sigma Aldrich" company (Germany) and diethylenetriamine produced by "Merck" company (Germany). Physicochemical properties of the initial used reactants are listing in Table 1.

\section{Table 1. Physicochemical properties of the used initial reactants.}

\begin{tabular}{ccc}
\hline Names of substances properties & N-hydroxyethyl ethylenediamine & Diethylenetriamine \\
\hline Molecular formula & $\mathrm{C}_{4} \mathrm{H}_{12} \mathrm{~N}_{2} \mathrm{O}$ & $\mathrm{C}_{4} \mathrm{H}_{13} \mathrm{~N}_{3}$ \\
Molecular mass, g/mol & 104.2 & 113.2 \\
Aggregate state & Viscous liquid & Liquid \\
Density at $20^{\circ} \mathrm{C}, \mathrm{g} / \mathrm{s} \cdot \mathrm{m}^{3}$ & 1.03 & 0.95 \\
Melting temperature, ${ }^{\circ} \mathrm{C}$ & -28 & -35 \\
Boiling temperature, ${ }^{\circ} \mathrm{C}$ & $238-240$ & $206-209$ \\
Color & Light yellow & Colorless \\
Degree of purity, $\%$ & 99 & 99 \\
Index of refraction $\left(\mathrm{n}_{\mathrm{D}}\right)$ & 1.4850 & 1.4826 \\
\hline
\end{tabular}


The composition of a mixture of fatty acids obtained by hydrolysis of cottonseed oil was determined according to ASTM D 6584 on the chromatograph Agilent 78A (the capillary column Zebron ZB-5HT Inferno, active phase of 5\% phenyl-95\% dimethylpolysiloxane, $15 \mathrm{~m} \times 0.32 \mathrm{~mm} \times 10 \mu \mathrm{m}$, the carrier gas-nitrogen) and is shown in Table 2.

The elemental composition of the obtained imidazolines was determined using device " 2400 CHN Elemental Analyzer" of "Perkin Elmer" Company.

As a source of ultrasonic vibrations there were used the ultrasonic processor UIP2000hd with the following specifications: COP > 85\%, the operating frequency $1-20 \mathrm{kHz}$, range of operating amplitudes $40 \%-100 \%$, power consumption 200 - $240 \mathrm{~V}$, AC frequency 48 - $63 \mathrm{~Hz}$.

The synthesis of the above listed imidazolines was conducted by the following procedure: in a four-neck flask equipped with an ultrasonic sonotrode, a thermometer, a Dean-Stark trap and a dropping funnel the calculated amount of the amine dissolved in $100 \mathrm{ml}$ of o-xylene is placed, the sonotrode is activated and the temperature of the mixture rises to the boiling point of o-xylene. Thereafter, through a dropping funnel during $20-25$ minutes the calculated amount of fatty acid previously diluted with o-xylene is given to the flask.

Water released at the stage of amidoamine formation was distilled in a Dean-Stark trap as an azeotrope with o-xylene. Upon termination of water extraction system is connected to a vacuum pump and the reaction continues until release of water formed as a result of the formation of imidazoline rings stops. Upon completion of the synthesis a viscous liquid was formed at the bottom of the flask.

In the second stage, the effects of imidazolines of cottonseed oil fatty acids on lubricity of hydrorefined low sulfur diesel fuel have been studied. As a base diesel fuel two (D-I and D-II) diesel fuels subjected to hydro refining and significantly different from each other in some quality indicators have been used and their properties are shown in Table 3.

The influence of the mentioned imidazolines on lubricity of DI and D-II diesel fuels was investigated on HFRR apparatus according to the CEC F-06-A-96 method. In the tests the temperature was $60^{\circ} \mathrm{C}$ and the volume of used fuel samples was $2 \mathrm{ml}$. The effectiveness of the fuel lubricity was evaluated with photomicroscope by measurement of wear scar diameter (WSD) of balls.

\section{Discussions and Conclusions}

\subsection{Synthesis of Fatty Acid Imidazolines}

The mechanism of the imidazolines synthesis reaction is following.

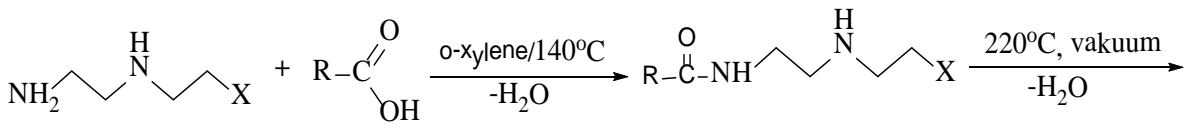

$$
\begin{aligned}
& \underset{-\mathrm{H}_{2} \mathrm{O}}{200^{\circ} \mathrm{C} \text {, vacuum }} \\
& \text { X-NH }{ }_{2}, \mathrm{OH}
\end{aligned}
$$

Table 2. Fatty acids of cottonseed oils.

\begin{tabular}{cc}
\hline Fatty acids & Content, \%wt \\
\hline Lauric (12:0) & - \\
Myristic (14:0) & 0.8 \\
Palmitic (16:0) & 22 \\
Stearic (18:0) & 2.5 \\
Oleic (18:1) & 30 \\
Linoleic (18:2) & 37.2 \\
Linolenic (18:3) & 7.5 \\
\hline
\end{tabular}


Table 3. Physical and chemical properties of diesel fuels used in the research.

\begin{tabular}{|c|c|c|}
\hline \multirow[t]{2}{*}{ Indicators } & \multicolumn{2}{|c|}{ Diesel fuels } \\
\hline & D-I & D-II \\
\hline Cetane number & 47 & 46 \\
\hline Density, $\mathrm{kg} / \mathrm{m}^{3}$ at $20^{\circ} \mathrm{C}$ & 849.5 & 851.0 \\
\hline Kinematic viscosity, $\mathrm{mm}^{2} / \mathrm{s}$ at $20^{\circ} \mathrm{C}$ & 2.23 & 2.29 \\
\hline Acidity, mg KOH/100s $\cdot \mathrm{m}^{3}$ fuel & 0.01 & 0.06 \\
\hline $\begin{array}{l}\text { Fractional composition, }{ }^{\circ} \mathrm{C} \\
\text { Boiling start } \\
10 \% \text { distillation temperature } \\
50 \% \text { distillation temperature } \\
90 \% \text { distillation temperature } \\
96 \% \text { distillation temperature }\end{array}$ & $\begin{array}{l}190 \\
210 \\
270 \\
335 \\
345\end{array}$ & $\begin{array}{l}196 \\
215 \\
275 \\
345 \\
350\end{array}$ \\
\hline Ignition temperature, ${ }^{\circ} \mathrm{C}$ & 73 & 74 \\
\hline $\begin{array}{c}\text { Hydrocarbon composition, \% } \\
\text { Aromatic } \\
\text { Paraffin-Naphthene } \\
\text { Unsaturated }\end{array}$ & $\begin{array}{c}21.23 \\
78.52 \\
0.25\end{array}$ & $\begin{array}{c}25.92 \\
72.38 \\
1.70\end{array}$ \\
\hline Total sulfur content, wt $\%$ & 0.0012 & 0.0035 \\
\hline Freezing point, ${ }^{\circ} \mathrm{C}$ & -36 & -35 \\
\hline Cloud point, ${ }^{\circ} \mathrm{C}$ & -28 & -30 \\
\hline Amount of water, \% & - & - \\
\hline Lubricity, $\mu \mathrm{m}$ (average value) & 620 & 601 \\
\hline
\end{tabular}

It is assumed that in this method of synthesis the effect of cavitation created by ultrasound provides the equal distribution of free molecules in the entire volume of solvent by breaking the hydrogen bond between acid and amine molecules and thus increases the possibility of their encountering. In addition it is assumed that the effect of cavitation weakens bonds between atoms within molecules, which are one of the necessary conditions for speeding up the reaction. However, the research conducted has proven that after the certain amplitude value of ultrasound the decomposition of molecules leads to additional reactions in the reaction mixture, which is undesirable. Given this the synthesis process has been conducted at the various values of ultrasound amplitude, temperature, molar ratio of the starting materials and reaction time and as a result the optimal conditions with the highest yield of the reaction product (imidazoline) for these factors were found (Table 4).

These studies have revealed the possibility of obtaining $\mathrm{N}$-(2-hydroxyethyl)- and $\mathrm{N}$-(2-aminoethyl)-imidazolines of fatty acids of cottonseed oil under the influence of ultrasonic cavitation with $90.2 \%-92.8 \%$ yield and a substantial reduction of reaction time compared to non-cavitational way of obtaining identical imidazolines from 12 - 22 hours to 4.5 - 5 hours.

The structure of the hydroxy- and aminoethyl imidazolines of fatty acids was confirmed by IR (500 - 3500 $\mathrm{cm}^{-1}$, Bruker) and NMR (300 MHz, Bruker) spectroscopy.

In the ${ }^{1} \mathrm{H}$ NMR spectrum of N-(2-aminoethyl)-imidazolines of fatty acids of cottonseed oil protons of amine group of the imidazoline appear as a singlet of one proton at $1.64-167 \mathrm{ppm}$, protons of methylene groups in the moieties $\mathrm{CH}_{2}-\mathrm{NH}_{2}, \mathrm{CH}_{2}-\mathrm{N}, \mathrm{N}-\mathrm{CH}_{2}$ and $\mathrm{CH}_{2} \mathrm{~N}=\mathrm{C}$ in the form of a triplet at $2.21-223,3.33-3.36,2.74-2.77$ and 3.63 - 368 ppm respectively.

In the ${ }^{13} \mathrm{C}$ NMR spectrum of the specified imidazoline the peak of the carbon atom in the moiety $-\mathrm{N}=\mathrm{CR}-\mathrm{N}$ appears at 165.8 - $166.1 \mathrm{ppm}$, the peaks of the carbon atom of methylene groups of $-\mathrm{CH}_{2}-\mathrm{N}=\mathrm{CR}$-moiety-at $50.7 \mathrm{ppm}, \mathrm{CH}_{2}-\mathrm{N}=-$ moiety - at $52.7-53.5 \mathrm{ppm}$, =N-CH -moiety—at $54.4-55.2 \mathrm{ppm}$, and $-\mathrm{CH}_{2}-\mathrm{NH}_{2}-\mathrm{moiety}-$ at $41.6-43.7 \mathrm{ppm}$.

In the IR spectrum 2-stearin- $\mathrm{N}$-(2-aminoethyl)imidazoline stretching vibrations of $\mathrm{NH}_{2}$-group appear at 3289 $\mathrm{s} \cdot \mathrm{m}^{-1}$, of $\mathrm{C}=\mathrm{N}$-group at $1637 \mathrm{~s} \cdot \mathrm{m}^{-1}$. 
Table 4. Yield of hydroxy- and aminoethyl imidazolines of fatty acids of cottonseed oil depending on the parameters of the process.

\begin{tabular}{cccccccc}
\hline Symbol & Acid & Amine & $\begin{array}{c}\text { Molar ratio } \\
\text { acid:amine }\end{array}$ & $\begin{array}{c}\text { Amplitude of ultrasonic } \\
\text { vibrations \% }\end{array}$ & $\begin{array}{c}\text { Duration of } \\
\text { reaction, hrs }\end{array}$ & $\begin{array}{c}\text { Temperature of } \\
\text { reaction, }{ }^{\circ} \mathrm{C}\end{array}$ & $\begin{array}{c}\text { Yield of } \\
\text { imidazolines, \% }\end{array}$ \\
\hline FA-Im $\left(\mathrm{NH}_{2}\right)$ & $\begin{array}{c}\text { Fatty } \\
\text { acid }\end{array}$ & DETA & $1: 1.5$ & 50 & 4.5 & 200 & 90.2 \\
FA-Im(OH) & HEED & $1: 1.5$ & 50 & 4.5 & 200 & 91.8 \\
\hline
\end{tabular}

\subsection{The Study of N-(2-Hydroxyethyl)- and N-(2-Aminoethyl)-Imidazolines of Fatty Acids of Cottonseed Oil as Antiwear Additives to Diesel Fuels}

In order to study the effects of FA-Im(OH)- and FA-Im( $\left(\mathrm{NH}_{2}\right)$ imidazolines on lubricity quality of D-I and D-II diesel fuels, in the first place the lubrication effect of D-I and D-II diesel fuels in their pure state was tested. It was found that when using D-I and D-II diesel fuels the WSD was 620 and $601 \mu \mathrm{m}$ respectively. The results show that, in fact, A-I and A-II diesel fuels do not meet the requirements for lubricity quality of modern diesel fuels (WSD $\leq 460 \mu \mathrm{m})$.

In order to study the influence of FA-Im(OH)- and FA-Im( $\left(\mathrm{NH}_{2}\right)$ imidazolines on lubricity quality of D-I and D-II low sulfur diesel fuels the WSD for D-I and D-II diesel fuels was determined after adding imidazolines to diesel fuels at 50 - 300 ppm. The WSD for each concentration was measured three times and eventually the average value of WSD was taken.

The curves of WSD dependence on concentration of imidazolines for D-I diesel fuel obtained from adding FA-Im(OH) and FA-Im(NH2) imidazolines to D-I and D-II diesel fuels are given in Figure 1.

As shown on Figure 1, the lubricity of D-I diesel fuel rises with the increase of imidazolines concentration in it. Thus, when concentration of FA-Im(OH) and FA-Im( $\left(\mathrm{NH}_{2}\right)$ imidazolines in the diesel fuel is 50 ppm the WSD is $600 \mu \mathrm{m}$ and $595 \mu \mathrm{m}$ respectively. When increasing the concentration from $50 \mathrm{ppm}$ to $250 \mathrm{ppm}$ the WSD for FA-Im(OH) imidazoline and FA-Im( $\left(\mathrm{NH}_{2}\right)$ imidazolines decreases to $474 \mu \mathrm{m}$ and to $465 \mu \mathrm{m}$ respectively. As seen from the results, the WSD values for FA-Im(OH) imidazoline at concentration of 300 ppm and for FA-Im $\left(\mathrm{NH}_{2}\right)$ imidazoline at concentration of $300 \mathrm{ppm}$ in D-I diesel fuel are less than $460 \mu \mathrm{m}$. This shows that at the indicated concentrations of imidazolines D-I diesel fuel meets the requirements for lubricity placed on modern diesel fuels. In addition, at concentration of FA-Im(OH) and FA-Im( $\left.\mathrm{NH}_{2}\right)$ higher than 300 ppm and 250 ppm respectively, no significant changes were observed in the lubricity quality of D-I diesel fuel. Therefore, the indicated concentrations can be considered as the optimal concentrations allowing to improve lubricity quality of D-I diesel fuel in accordance with modern quality standards.

In the research work, the effects of FA-Im(OH)- and FA-Im( $\left(\mathrm{NH}_{2}\right)$ imidazolines on lubricity quality of D-II low sulfur diesel fuel were also studied.

In Figure 2 the curves of WSD dependence on concentration of imidazolines have been given for D-II diesel fuel with added FA-Im(OH)- and FA-Im( $\left(\mathrm{NH}_{2}\right)$ imidazolines.

As shown on Figure 2, similar to D-I diesel fuel with the increase of concentrations of FA-Im(OH) and FA-Im( $\left.\mathrm{NH}_{2}\right)$ in D-II diesel fuel the lubricity quality of the diesel fuel rises. Thus, when increasing the concentration of FA-Im(OH)- and FA-Im( $\left.\mathrm{NH}_{2}\right)$ in D-II diesel fuel from 50 ppm to 250 ppm the WSD for FA-Im(OH) and FA-Im( $\left(\mathrm{NH}_{2}\right)$ decreases from $585 \mu \mathrm{m}$ to $463 \mu \mathrm{m}$ and from $577 \mu \mathrm{m}$ to $454 \mu \mathrm{m}$, respectively. As can be seen from the results, the optimal concentrations of FA- $\operatorname{Im}(\mathrm{OH})$ and FA-Im( $\left(\mathrm{NH}_{2}\right)$ in D-II diesel fuel are 300 and 250 ppm, respectively. Thus, in concentration of FA-Im(OH)-imidazoline 300 ppm and concentration of FA-Im( $\left(\mathrm{NH}_{2}\right)$ $250 \mathrm{ppm}$ in D-II diesel fuel the WSD value is lower than the modern requirement (460 $\mu \mathrm{m})$.

According to the results obtained it can be noted that by applying the effect of cavitation created by ultrasound to the classical method of imidazolines synthesis the reduction of synthesis duration 2 - 5 times compared to other methods of synthesis and the yield of imidazolines $92 \%$ - 97\% can be achieved. On the other hand, the comparison of the effect of $F A-\operatorname{Im}(\mathrm{OH})$ and $F A-\operatorname{Im}\left(\mathrm{NH}_{2}\right)$ on lubricity of both diesel fuels shows that compared to FA- $\operatorname{Im}(\mathrm{OH})$ the effect of FA-Im( $\left.\mathrm{NH}_{2}\right)$ imidazoline on lubricity of diesel fuels is higher. The reason for this can be given that because of the lower electronegativity of nitrogen atom compared to oxygen atom electrons in the amino group can easily form bonds with rubbed surfaces at the expense of electron gas.

This causes the recovery of the layer destroyed in the process of friction in a short period of time and thus rubbed surfaces wear away in a less degree. 


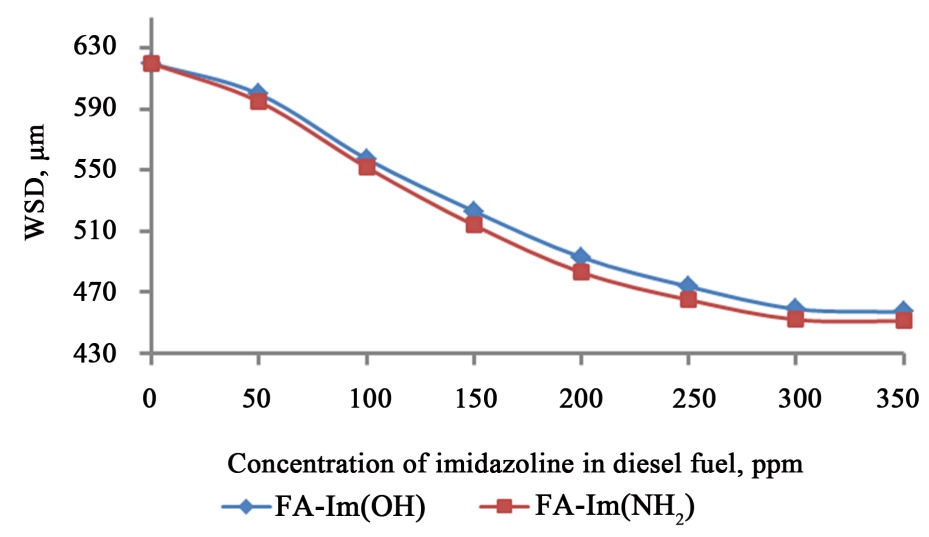

Figure 1. The effect of FA-Im(OH) and FA-Im( $\left(\mathrm{NH}_{2}\right)$ imidazolines on lubricity quality of D-I diesel fuel.

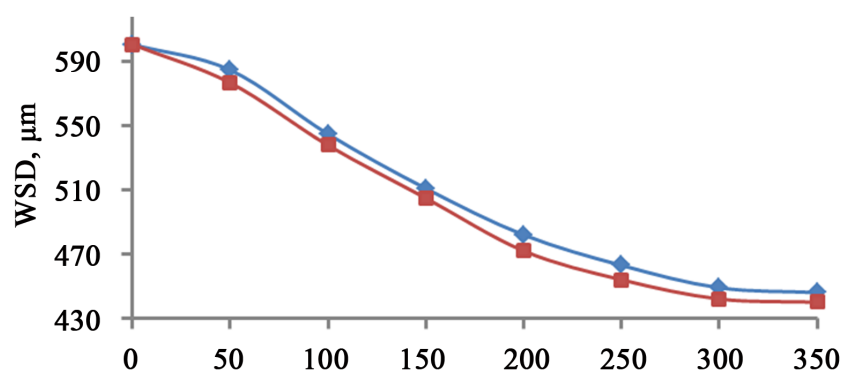

Concentration of imidazoline in diesel fuel, ppm

$\rightarrow$ FA-Im(OH) $\rightarrow$ FA-Im( $\left(\mathrm{NH}_{2}\right)$

Figure 2. The effect of FA-Im(OH) and FA-Im( $\left(\mathrm{NH}_{2}\right)$ imidazolines on lubricity quality of D-II diesel fuel.

In addition, according to the curves in Figure 1 and Figure 2, very insignificant differences between them are observed. This shows that the application of imidazolines to diesel fuel as lubricity-enhancing additives depends insignificantly on the hydrocarbon composition of diesel fuel.

Finally, it should be noted that FA-Im( $(\mathrm{OH})$ and FA-Im $\left(\mathrm{NH}_{2}\right)$ imidazolines can be used as additives enhancing the lubricity of diesel fuels.

\section{References}

[1] Knapp, G.G. (1984) Corrozion Inhibitors for Alcohol Containing Motor Fuel. US Patent No. 4511367 A.

[2] Martin, E.C. and Titsworth, H.R. (1960) Rust Inhibitor for Gasoline. US Patent No. 2919979.

[3] Marshall, D.E. and Kenneth, D.L. (1981) Antirust Fuel Composition. US Patent No. 4263014.

[4] Karavalakis, G.S. and Stournas, S.D. (2010) Impact of Antioxidant Additives on the Oxidation Stability of Diesel/Biodiesel Blends. Energy Fuels, 24, 3682-3686. http://dx.doi.org/10.1021/ef1004623

[5] Kenneth, D.L. (1970) Thixotropic Oil-in-Water Emulsion Fuels. US Patent No. 3490237.

[6] Meyer, G.R. (2013) Alkyl Imidazolines and Their Ehoxylated Derivatives as Antioxidants. Journal of Petroleum Science and Technology, 3, 1-7.

[7] Panteleev, E.V. (2007) Additive to Motor Fuel. Diesel Fuel. RU Patent No. 2355732.

[8] Zadko, I.I., Bajenov, V.P., Ermolayev, M.P., et al. (1999) Fuel Composition. RU Patent No. 2126032.

[9] Khille, M., Kupher, R. and Bem, R. (2002) Alkoxylated Fatty Amines and Derivatives Thereof. RU Patent No. 2122563.

[10] Vataru, M. and Filowitz, M.S. (1989) Diesel Fuel Additive. US Patent No. 4857073 A.

[11] Farkhani, D., Rezaei, H., Gholami, N., Sina, M., Khalili, A.A. and Mehdizadeh, A. (2013) Alkyl Imidazolines and 
Their Ethoxylated Derivatives as Antioxidants for Hydrocarbon Products. Journal of Petroleum Science and Technology, 3, 1-7.

[12] Drozd, J.C., Martin, H.R., Blakemore, T.J., et al. (2004) Controlled Release Additives in Fuel Systems. US Patent No. 6827750 B2.

[13] Drozd, J.C. and Martin, H.R. (2001) Fuel Additive Compositions. US Patent No. 6835218 B1.

[14] Schield, J.A. and Biggerstaff, P.J. (2011) Branched Carboxylic Acids as Fuel Lubricity Additives. US Patent No. 7867295 B2.

[15] Hoang, V. Q., Leung, P.L. and Rivers, G.T. (2013) No-Sulfur Fuel Lubricity Additive. US Patent No. 8425628 B2.

[16] William, F. (1999) Acylated Imidazolines and Fuel and Lubricant Compositions Thereof. EP Patent No. 0074724 A2. 